Article

\title{
Lubrication Properties of Bio-Oil and Its Emulsions with Diesel Oil
}

\section{Qiang Lu *, Zhi-Bo Zhang, Hang-Tao Liao, Xiao-Chu Yang and Chang-Qing Dong}

National Engineering Laboratory for Biomass Power Generation Equipment, North China Electric Power University, Beijing 102206, China; E-Mails: epubnbn@126.com (Z.-B.Z.); liaohangtao@126.com (H.-T.L.); yangxiaochu@yahoo.cn (X.-C.Y.); cqdong1@163.com (C.-Q.D.)

* Author to whom correspondence should be addressed; E-Mail: qianglu@mail.ustc.edu.cn; Tel.: +86-10-6177-2032 (ext. 805); Fax: +86-10-6177-2032 (ext. 801).

Received: 23 January 2012; in revised form: 4 March 2012 / Accepted: 6 March 2012 /

Published: 14 March 2012

\begin{abstract}
Bio-oil from fast pyrolysis of biomass is a low-grade liquid fuel, which can be upgraded through the emulsification with diesel oil. In this study, we prepared two rice husk bio-oil samples with different solid char contents and three bio-oil/diesel-oil emulsion samples with the bio-oil content of $10 \mathrm{wt} \%, 30 \mathrm{wt} \%$ and $50 \mathrm{wt} \%$, respectively. The lubrication properties of these oil samples were evaluated by a four-ball tester. The morphologies of the worn ball surface were observed by scanning electron microscope (SEM). The chemical states of the elements on the worn surface and non-worn surface were analyzed by X-ray photoelectron spectroscope (XPS). The results showed that the bio-oil possessed better extreme-pressure, anti-wear and friction-reducing properties than the commercial diesel oil (number zero). The solid char particles in the bio-oil could improve its lubrication performance. Moreover, the lubrication ability of the emulsions would be enhanced with the increasing of the bio-oil content in the emulsions.
\end{abstract}

Keywords: bio-oil; lubrication property; emulsion; four-ball tester; SEM; XPS 


\section{Introduction}

Fast pyrolysis of biomass is a thermal decomposition process that occurs in the absence of oxygen to convert solid biomass mainly into a liquid product known as bio-oil [1,2]. This technology has gained extensive attention in recent years, as bio-oil is regarded as a promising candidate of petroleum fuels $[3,4]$. However, bio-oil is totally different from petroleum oils, it is a complex mixture of water (15-35 wt\%), solid particles $(0.01-3 \mathrm{wt} \%)$ and hundreds of organic compounds that belong to acids, aldehydes, ketones, phenols, alcohols, ethers, esters, sugars, furans, nitrogen compounds as well as large molecular oligomers [5]. Due to the unique composition, bio-oil is highly oxygenated, acid and corrosive to common materials, thermally and chemically instable, as well as non-miscible with petroleum fuels [6]. These poor fuel properties make bio-oil only possible to be used in boilers and furnaces, but hard to be directly used in diesel engines and gas turbines [7]. To overcome these disadvantages, various physical or chemical methods have been proposed to upgrade bio-oil. One of them is the emulsification of the bio-oil with diesel oil (or bio-diesel oil) by the proper surfactants to obtain homogenous emulsions [8-13]. The bio-oil/diesel-oil emulsions have much better fuel properties than the crude bio-oil. Some preliminary studies indicated that the emulsions could be successfully utilized in internal combustion engines [14].

During the combustion of a liquid fuel, fuel injection systems should be lubricated primarily by the fuel itself. Fuels of poor lubricity will cause significant wear problems. Till now, very limited studies are available to report the lubricity of the bio-oil based fuels. Oasmaa et al. analyzed the lubricity of a bio-oil sample prepared from the Ensyn RTP fast pyrolysis process, by using a high frequency friction tester and a four-ball wear machine [15]. Due to the volatility of the bio-oil, the open high frequency friction tester was unable to measure the lubricity of the bio-oil. Whereas the results of the four-ball machine confirmed that the bio-oil possessed some lubricity. In addition, $\mathrm{Xu}$ et al. distilled a rice husk bio-oil at reduced pressure, and then mixed the distillation fraction with the diesel oil to make an emulsion sample. A high frequency reciprocating test rig was employed to analyze its lubricity. The results revealed that the emulsion sample possessed better fraction reduction property, but worse wear resistance property than the commercial diesel oil (number zero) [16].

In this study, we prepared two bio-oil samples with different solid char contents and three bio-oil/diesel-oil emulsion samples with different bio-oil contents. Their lubrication properties were evaluated by a four-ball tester, to reveal the effects of the char particles on the lubricity performance of the bio-oil, and to compare the lubricity of the bio-oil, diesel oil and bio-oil/diesel-oil emulsions. Moreover, the worn ball surface was analyzed with SEM and XPS to determine the changes of the surface chemistry.

\section{Experimental}

\subsection{Bio-Oil}

The bio-oil used in this study was produced by an auto-thermal fast pyrolysis pilot set with the capacity of $120 \mathrm{~kg} / \mathrm{h}$ [17]. Rice husk was used as the feedstock and pyrolyzed at $748 \mathrm{~K}$ to obtain the crude bio-oil (CBO) with the yield of $50 \mathrm{wt} \%$. The $\mathrm{CBO}$ had the solid char content as high as $0.8 \mathrm{wt} \%$, due to the insufficient separation capability of the cyclones on small solid char particles. Hence, it was 
centrifuged to get rid of some char particles. The obtained bio-oil (BO) was stored in oil tanks and used as the mother liquid for preparation of bio-oil/diesel-oil emulsions. The char content of the BO was only $0.4 \mathrm{wt} \%$. The elemental composition (on wet basis) and the basic fuel properties of the BO are presented in Tables 1 and 2.

Table 1. Elemental composition of the BO.

\begin{tabular}{ccccccccccc}
\hline $\mathbf{C}$ & $\mathbf{H}$ & $\mathbf{N}$ & $\mathbf{O}$ & $\mathbf{S}$ & $\mathbf{S i}$ & $\mathbf{N a}$ & $\mathbf{K}$ & $\mathbf{C a}$ & $\mathbf{M g}$ & $\mathbf{F e}$ \\
\hline 37.48 & 8.28 & 0.59 & 53.45 & 0.036 & 0.092 & 0.001 & 0.010 & 0.006 & 0.002 & 0.053 \\
\hline
\end{tabular}

\subsection{Preparation and Characterization of Bio-Oil/Diesel-Oil Emulsions}

Commercial number zero diesel oil (DO) was bought from market (National Standard of China GB2522-000). Three bio-oil/diesel-oil emulsion oils (EO) were prepared using an ultrasonic emulsifier. The bio-oil content in the three EO samples was $10 \mathrm{wt} \%, 30 \mathrm{wt} \%$ and $50 \mathrm{wt} \%$, while the surfactant content was $3 \mathrm{wt} \%$. The surfactant was a mixture of Span 20, Span 80 and Span 100, at the content of $20 \mathrm{wt} \%, 20 \mathrm{wt} \%$ and $60 \mathrm{wt} \%$, respectively. The three EO samples are referred to as EO10, EO30 and EO50 in this paper. They were single-phase liquids, and could keep stable without phase separation for at least one day at room temperature. In the EO10 and EO30, the DO was the continuous phase, and the $\mathrm{BO}$ droplets were dispersed in the DO matrix. Whereas the EO50 was a bicontinuous emulsion as both of the BO and DO were continuous. The basic fuel properties of the DO, EO10, EO30 and EO50 are also shown in Table 2.

Table 2. Fuel properties of the BO, DO and their emulsions.

\begin{tabular}{cccccc}
\hline Sample & HHV(MJ/kg) & $\begin{array}{c}\text { Water } \\
(\mathbf{w t} \%)\end{array}$ & $\begin{array}{c}\text { Density } \\
(\mathbf{g} / \mathbf{m L})\end{array}$ & $\begin{array}{c}\text { Kinematic viscosity } \\
(\mathbf{c S t}, \mathbf{3 1 3} \mathbf{~ K})\end{array}$ & $\begin{array}{c}\mathbf{p H} \\
\mathbf{( - )}\end{array}$ \\
\hline BO & 15.4 & 32.3 & 1.13 & 10.2 & 3.2 \\
DO & 44 & - & 0.85 & 2.9 & 7.8 \\
EO10 & 41.9 & 3.3 & 0.88 & 4.9 & 3.4 \\
EO30 & 35.5 & 9.7 & 0.93 & 8.0 & 3.3 \\
EO50 & 29.8 & 16.2 & 0.99 & 15.3 & 3.2 \\
\hline
\end{tabular}

\subsection{Lubricity Analysis}

The lubrication properties of the oil samples were determined by the tribological tests on an MQ-800 four-ball machine at ambient temperature $(298 \mathrm{~K})$. The extreme-pressure tests were firstly performed to determine the maximum nonseizure load $\left(P_{\mathrm{B}}\right)$ values of the oil samples, according to Chinese national standard method GB/T12583 (similar to ASTM D2783). The rotating speed was 1450 rpm and the test duration was $10 \mathrm{~s}$. Afterwards, the friction and wear tests were conducted to determine the anti-wear and friction-reducing properties of the oil samples under the following conditions: rotating speed $1450 \mathrm{rpm}$, test duration $30 \mathrm{~min}$, load $196 \mathrm{~N}$ or $392 \mathrm{~N}$. The wear scar diameters (WSD) of the three lower balls were observed with an optical microscope and averaged as the WSD values reported in the paper. The friction coefficient was automatically measured and recorded. The balls (diameter $12.7 \mathrm{~mm}$ ) used in the tests were made of GCr 15 bearing steel with a hardness of HRc 596-1. 


\subsection{Worn and Non-Worn Ball Surface Analysis}

Before analysis, the balls were washed with the methanol/dichloromethane mixture for 5 min, and then gently wiped with tissue paper to remove the loosely attached materials. The morphologies of the worn surface were observed by SEM (X-650). The chemical states of the elements on the worn surface and non-worn surface were studied by XPS (Thermo ESCALAB 250) with a monochromatized Al Ka source $(1486.6 \mathrm{eV})$. The pass energy was $20 \mathrm{eV}$. Internal calibration was referenced to the $\mathrm{C}-(\mathrm{C}, \mathrm{H})$ components of the $\mathrm{C} 1 \mathrm{~s}$ spectra at the binding energy (BE) of $284.8 \mathrm{eV}$. After subtraction of a nonlinear background, the spectra were deconvoluted by using the peak fitting software.

\subsection{Thermogravimetric Analysis of the Bio-Oil Sample}

The original BO sample and the used BO sample (after the friction and wear test under the load of $392 \mathrm{~N}$ ) were subjected to thermogravimetric analysis using a DTG-60H analyzer. About $10 \mathrm{mg}$ oil sample was heated from room temperature to $823 \mathrm{~K}$ under the nitrogen atmosphere, with a constant heating rate of $10 \mathrm{~K} / \mathrm{min}$ and the gas flow rate of $50 \mathrm{~mL} / \mathrm{min}$.

\section{Results and Discussion}

\subsection{Thermogravimetric Analysis Results}

The four-ball tester is a closed machine, but not air-tight. Bio-oil contains some low-boiling compounds, such as formaldehyde (b.p. $253.7 \mathrm{~K})$, acetaldehyde $(294.0 \mathrm{~K})$, glyoxal $(323.7 \mathrm{~K})$ and acetone $(329.7 \mathrm{~K})$. During the friction and wear tests, heat generated from friction would increase the oil temperature, resulting in evaporation of some light volatiles. In the previous study performed by Oasmaa et al. [15], when an open High Frequency Friction equipment was employed for experiments, significant evaporation of the bio-oil took place which disturbed the measurement. Therefore, thermogravimetric analysis was performed on the original and used BO samples, to confirm whether the four-ball machine was able to evaluate the lubricity of the bio-oil.

Figure 1. TG and DTG curves of the original BO sample (a) and the BO sample after the friction and wear test (b).
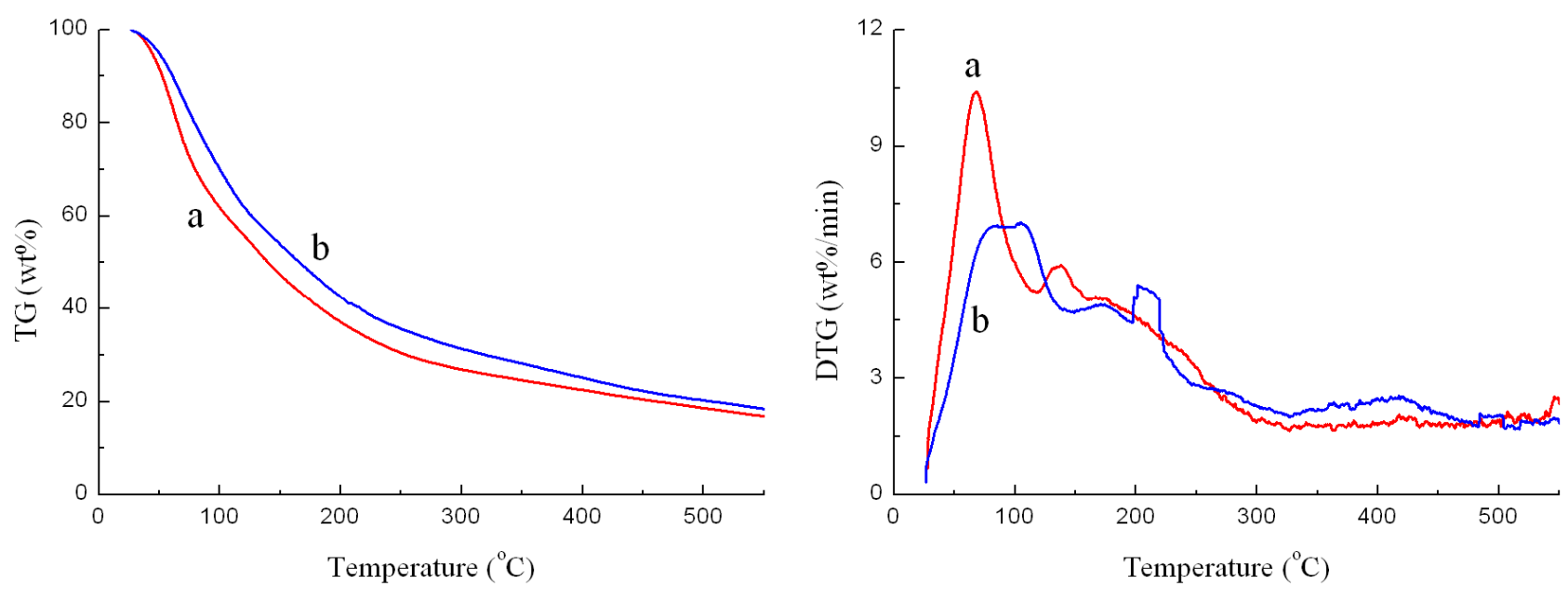
The experimental data of the weight loss (TG) and weight loss rates (DTG) of the two samples are shown in Figure 1. It is clear that the used BO sample contained less light volatile compounds than the original BO sample, which indicated that evaporation of light volatiles took place during the test, but not severe. Therefore, we might infer that the four-ball tester was able to evaluate the lubricity of the bio-oil.

\subsection{Lubrication Properties}

The extreme-pressure, anti-wear and friction-reducing properties of the oil samples are evaluated by the $P_{\mathrm{B}}$, WSD and friction coefficient values, respectively. Table 3 shows the $P_{\mathrm{B}}$ values of all the oil samples. Table 4 gives the WSD and friction coefficient values of the BO, CBO and DO samples tested under the load of $196 \mathrm{~N}$. Table 5 gives the WSD and friction coefficient values of the BO, EO10, EO30 and EO50 samples tested under the load of $392 \mathrm{~N}$.

Table 3. $P_{\mathrm{B}}$ values of the oil samples.

\begin{tabular}{ccccccc}
\hline Sample & BO & CBO & DO & EO10 & EO30 & EO50 \\
\hline$P_{\mathrm{B}}(\mathrm{N})$ & 470 & 510 & 333 & 470 & 510 & 510 \\
\hline
\end{tabular}

Table 4. WSD and friction coefficient values of the BO, CBO and DO tested under $196 \mathrm{~N}$.

\begin{tabular}{cccc}
\hline Sample & BO & CBO & DO \\
\hline WSD $(\mathrm{mm})$ & 0.53 & 0.50 & 0.57 \\
Friction coefficient & 0.057 & 0.034 & 0.108 \\
\hline
\end{tabular}

Table 5. WSD and friction coefficient values of the BO, EO10, EO30 and EO50 tested under $392 \mathrm{~N}$.

\begin{tabular}{ccccc}
\hline Sample & BO & EO10 & EO30 & EO50 \\
\hline WSD $(\mathrm{mm})$ & 0.89 & 1.20 & 0.92 & 0.75 \\
Friction coefficient & 0.069 & 0.127 & 0.093 & 0.076 \\
\hline
\end{tabular}

According to Table 3 and Table 4, the $\mathrm{BO}$ and $\mathrm{CBO}$ had higher $P_{\mathrm{B}}$ values, smaller WSD and friction coefficient values than the DO. It clearly indicated that the rice husk bio-oil possessed better extreme-pressure, anti-wear and friction-reducing properties than the commercial diesel oil (number zero). Therefore, we can conclude that the rice husk bio-oil owned some lubricity, which might be due to its polar and highly oxygenated chemical nature. Polar compounds in the bio-oil were easy to adsorb on metal surface and thus forming protective films which could prevent the ball surface from significant wear.

In addition, the $\mathrm{CBO}$ exhibited better extreme-pressure, anti-wear and friction-reducing properties than the BO, suggesting that the solid char particles could improve the lubrication performance of the bio-oil. It might be attributed to the fact that char particles were easy to adsorb on the metal surface and thus acting as solid lubricants. However, the presence of char particles is believed to bring many negative effects to the storage and combustion of bio-oil, because they can accelerate the ageing of bio-oil and cause significant high-temperature corrosion to the internal-combustion engines. Hence, char particles should be removed from bio-oil, but it is difficult to completely remove the chars by filtration of the liquid bio-oil [18]. Currently, hot vapor filtration is the only effective method to 
prepare bio-oil with very low solid content $[19,20]$, but it has not been well applied even at pilot-scale. Further studies will be performed to determine the lubricity of the vapor-filtered bio-oil.

According to Table 3 and Table 5, the three EO samples all had high $P_{\mathrm{B}}$ values, suggesting their good extreme-pressure property. The rank of the WSD values was EO10 $>$ EO30 $>\mathrm{BO}>\mathrm{EO} 50$, which indicated that the anti-wear property of the $\mathrm{BO}$ was better than the EO10 and EO30, but worse than the EO50. The rank of the friction coefficient values was EO10 $>\mathrm{EO} 30>\mathrm{EO} 50>\mathrm{BO}$, illustrating that the BO possessed the best friction-reducing property of the four samples. Generally, the lubricity of the three EO samples was improved with the increasing of the bio-oil concentrations. The lubricity of the EO10 was relatively poor, which might be due to its low bio-oil content, and thus the EO10 was unable to generate effective protective films.

\subsection{SEM Analysis}

Figure 2 shows the SEM images of the worn surface of the upper balls lubricated with the BO, EO10, EO30 and EO50 under $392 \mathrm{~N}$. The worn surface lubricated with the EO10 was characterized by obvious scuffing. Whereas the scuffing was abated to smaller degrees for the worn surface lubricated with the EO30, EO50 and BO, suggesting that the corresponding boundary lubricating films at these conditions had good strength.

Figure 2. SEM images of the worn surface lubricated with the EO10 (a,b), EO30 (c,d), EO50 (e,f) and BO (g,h) under $392 \mathrm{~N}$.

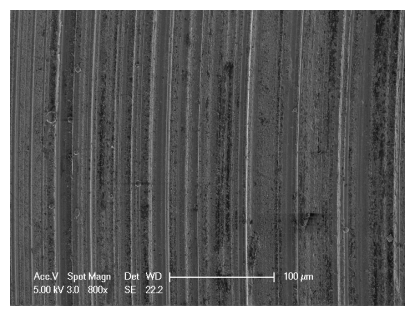

(a)

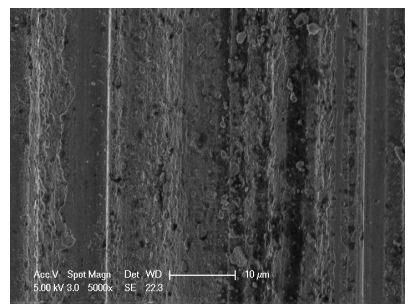

(b)

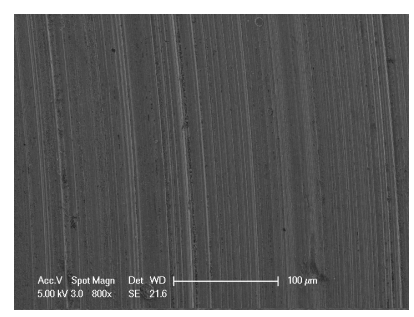

(c)

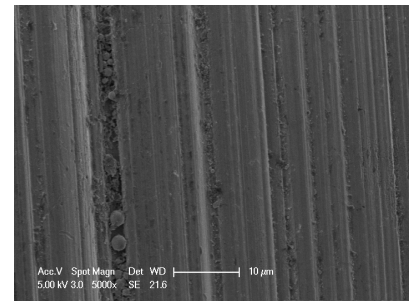

(d)

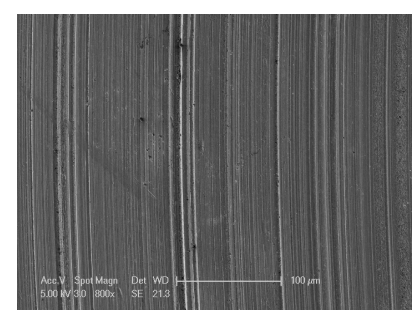

(e)

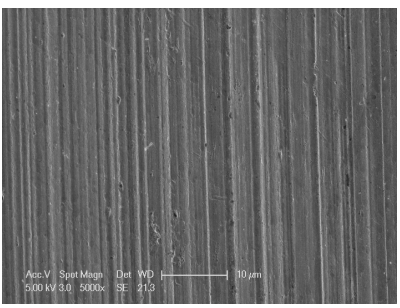

(f)

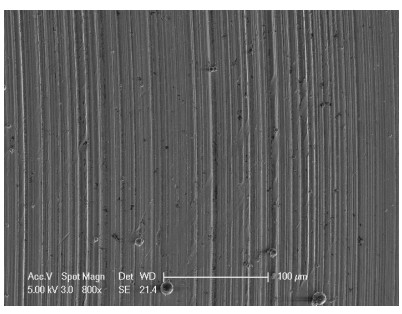

(g)

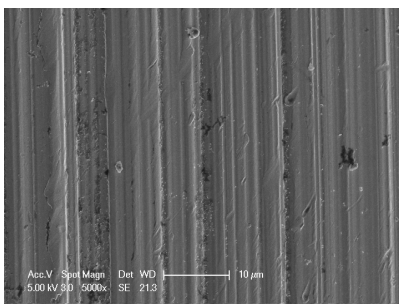

(h)

\subsection{XPS Analysis}

During the friction and wear tests, deposits would be covered on ball surface in contact with bio-oil, resulting from the chemical adsorption of highly polar compounds and polymerization reactions of unstable compounds [21]. In addition, tribochemical reactions would take place to add materials to the deposits on the worn surface to form lubricating films. The formation of deposits was evidenced by the pronounced darkening of the balls after tests. Therefore, XPS analysis was performed to investigate the chemical nature of the deposits on both of worn and non-worn surface. 
The carbon, oxygen and iron were detected as the major elements on the worn and non-worn surface by XPS. The C 1s and O 1s XPS spectra could be used to reveal the chemical nature of the organic compounds in the deposits, as shown in Figure 3 and Figure 4. It is to note that the carbon and oxygen were also detected on the untreated new ball, because metals exposed in air would react with oxygen to form metal oxides and also adsorb many organic contaminants. Hence, the $\mathrm{C} 1 \mathrm{~s}$ and $\mathrm{O}$ 1s spectra of the untreated ball are also given in Figure 3 and Figure 4 as the reference spectra. All the spectra were fitted to three peaks. According to the $\mathrm{C}$ 1s spectra, the present forms of carbon could be determined as: (I) carbon bonded to carbon or hydrogen, $\mathrm{C}-\mathrm{C}$ or $\mathrm{C}-\mathrm{H}$, at around the $\mathrm{BE}$ of $284.8 \mathrm{eV}$; (II) carbon singly bonded to oxygen, $\mathrm{C}-\mathrm{O}-\mathrm{H}$ or $\mathrm{C}-\mathrm{O}-\mathrm{C}$, at around the $\mathrm{BE}$ of $286.6 \mathrm{eV}$; (III) carbon doubly bonded to oxygen, $\mathrm{C}=\mathrm{O}$, at around the $\mathrm{BE}$ of $288.5 \mathrm{eV}$. Based on the $\mathrm{O} 1 \mathrm{~s}$ spectra, the present forms of oxygen could be determined as: (I) metal oxides $\left(\mathrm{Fe}_{2} \mathrm{O}_{3}\right.$ and $\left.\mathrm{Fe}_{3} \mathrm{O}_{4}\right)$, at around the $\mathrm{BE}$ of $529.0 \mathrm{eV}$; (II) $\mathrm{C}=\mathrm{O}$, at around the $\mathrm{BE}$ of $531.5 \mathrm{eV}$; (III) $\mathrm{C}-\mathrm{O}-\mathrm{H}$ or $\mathrm{C}-\mathrm{O}-\mathrm{C}$, at around the $\mathrm{BE}$ of $533.0 \mathrm{eV}$.

Figure 3. Deconvoluted C 1s XPS spectra of the untreated new ball (a) and balls lubricated with EO10 (b), EO30 (c), EO50 (d) and BO (e) under 392 N.

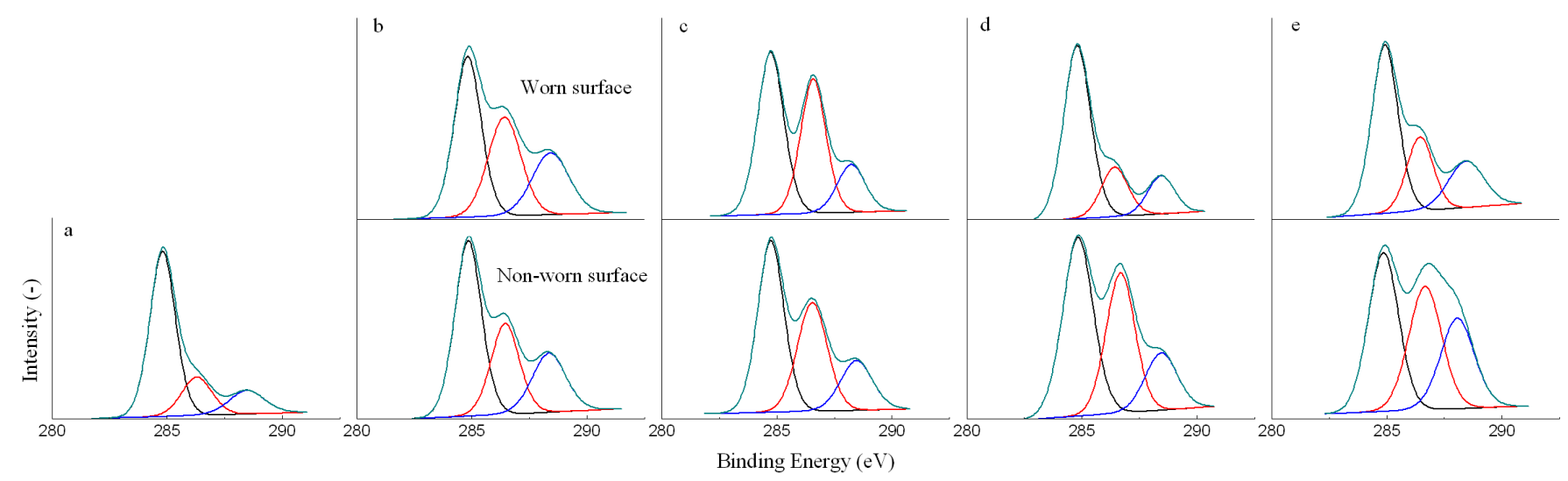

Figure 4. Deconvoluted O 1s XPS spectra of the untreated new ball (a) and balls lubricated with EO10 (b), EO30 (c), EO50 (d) and BO (e) under 392 N.

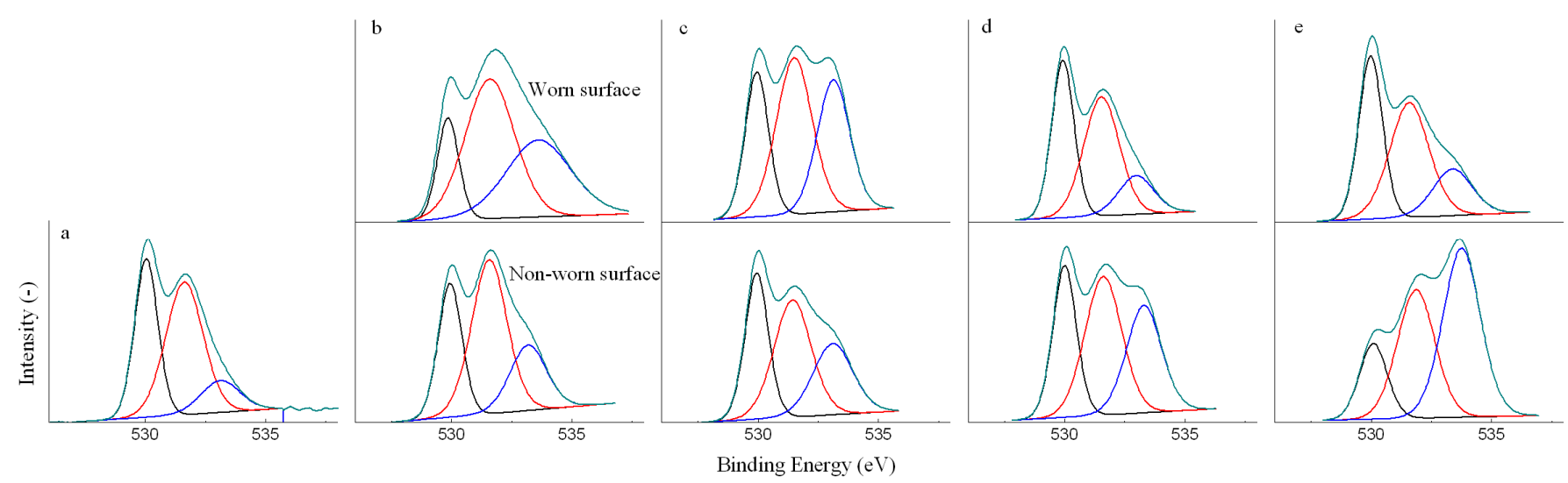

Compared with the untreated new ball, the relative abundance of the carbon and oxygen in forms of $\mathrm{C}-\mathrm{O}-(\mathrm{H}, \mathrm{C})$ and $\mathrm{C}=\mathrm{O}$ was increased after tests on both of worn and non-worn surface, while the relative abundance of the carbon and oxygen in forms of $\mathrm{C}-(\mathrm{C}, \mathrm{H})$ and metal oxides was decreased. It indicated 
that the deposits contained oxygenated compounds from the bio-oil. However, XPS was unable to reveal more information about the composition of the organic deposits, and also unable to differentiate the organic deposits on the worn and non-worn surface.

Figure 5 shows the Fe 2p XPS spectra of the ball lubricated with the EO50. The balls lubricated with other oil samples had similar Fe $2 p$ XPS spectra. The spectra consisted of two peaks at around $707 \mathrm{eV}$ and $711 \mathrm{eV}$. The first peak was attributable to metallic iron. The BE value of the second peak was between the $\mathrm{BE}$ values of $\mathrm{Fe}_{3} \mathrm{O}_{4}$ and $\mathrm{Fe}_{2} \mathrm{O}_{3}$, indicating the presence of both of $\mathrm{Fe}_{3} \mathrm{O}_{4}$ and $\mathrm{Fe}_{2} \mathrm{O}_{3}$. The second peak might also contain the contribution from $\mathrm{FeSO}_{4}$, which will be revealed by the $\mathrm{S} 2 \mathrm{p}$ spectra below. The second peak was much more intense than the first peak. It meant that the ball surface was covered with thick metal oxides and organic deposits, and thus only a little metallic iron was detected.

Sulfur was detected on all worn surface and some non-worn surface. The S $2 p$ XPS spectra of the ball lubricated with the EO50 are given in Figure 6. The spectra showed a weak peak at around $168.8 \mathrm{eV}$, attributable to $\mathrm{FeSO}_{4}$. The inorganic $\mathrm{FeSO}_{4}$ was existed in the ash of solid char particles, which confirmed the fact that solid char particles could adsorb on the ball surfaces during the tests. Moreover, the sulfur contents on the worn surface (determined by XPS) were much higher than those in the oils, suggesting the strong adsorption of char particles. The presence of sulfate in lubricating films is believed to improve the lubrication properties of liquid fuels [22].

Figure 5. Fe 2p XPS spectra of the ball lubricated with the EO50.

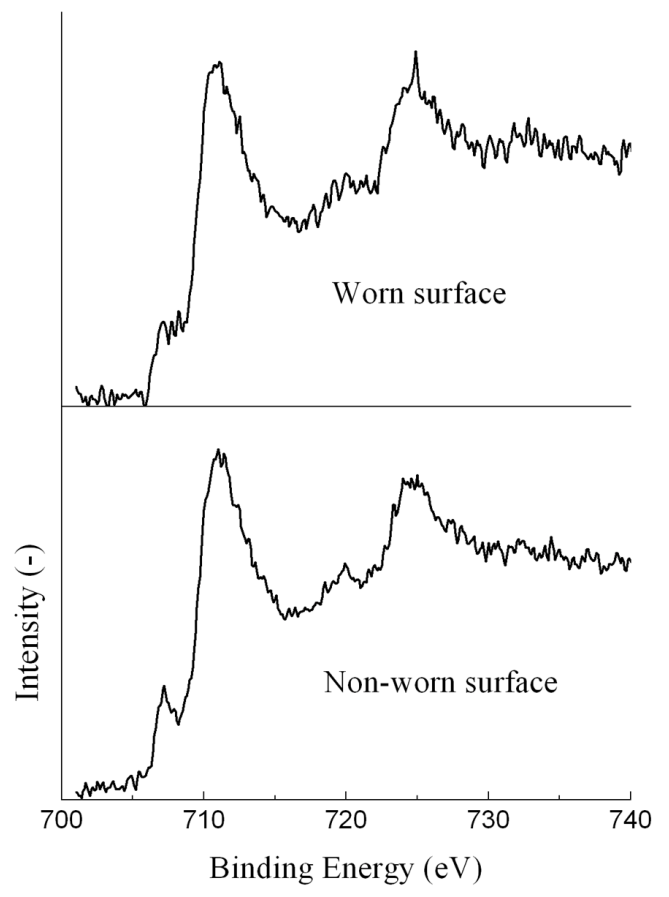

In addition, nitrogen was detected on all worn and non-worn surfaces. The N 1s XPS spectra of the ball lubricated with the EO50 are shown in Figure 7. The peak located at around $400 \mathrm{eV}$ was assigned to organic nitrogen compounds. The nitrogen contents on the ball surface (determined by XPS) were much higher than those in the oils, suggesting the strong adsorption of nitrogen-containing compounds. However, we could not determine the structure of the nitrogen-containing compounds, and thus, did not know how these nitrogen compounds would affect the lubricity of the bio-oil. 
The above results indicated that the lubricating films formed on worn surface were thick and complex. They were composed of organic oxygenated deposits, metal oxides, char particles, sulfate and organic nitrogen compounds. However, due to the limitation of the XPS method, it was unable to reveal the difference of the lubricating films generated by different oil samples, and also unable to determine the difference of the lubricating films on the worn surface and the deposits on the non-worn surface.

Figure 6. S 2p XPS spectra of the ball lubricated with the EO50.

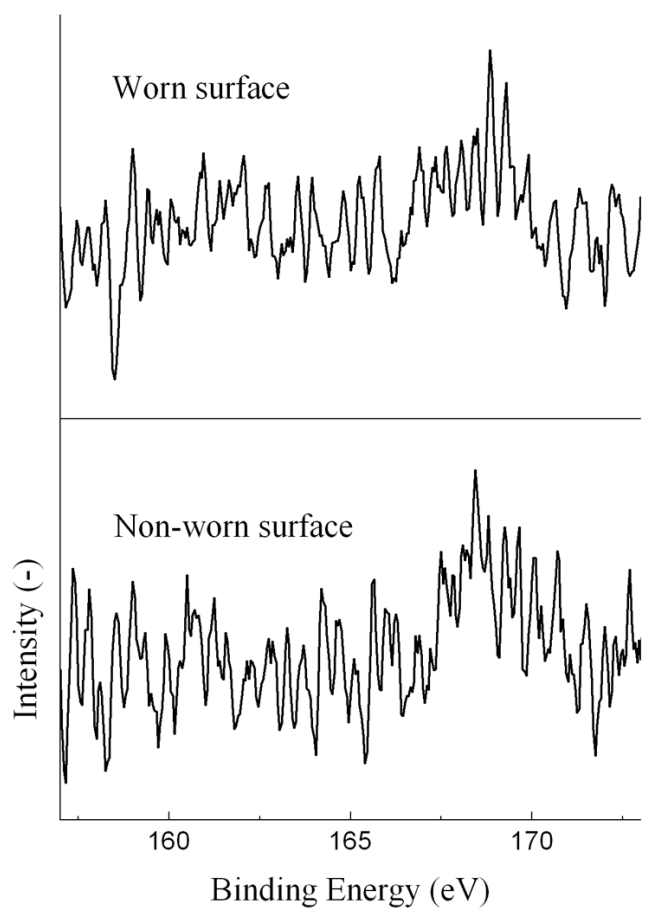

Figure 7. N 1s XPS spectra of the ball lubricated with the EO50.

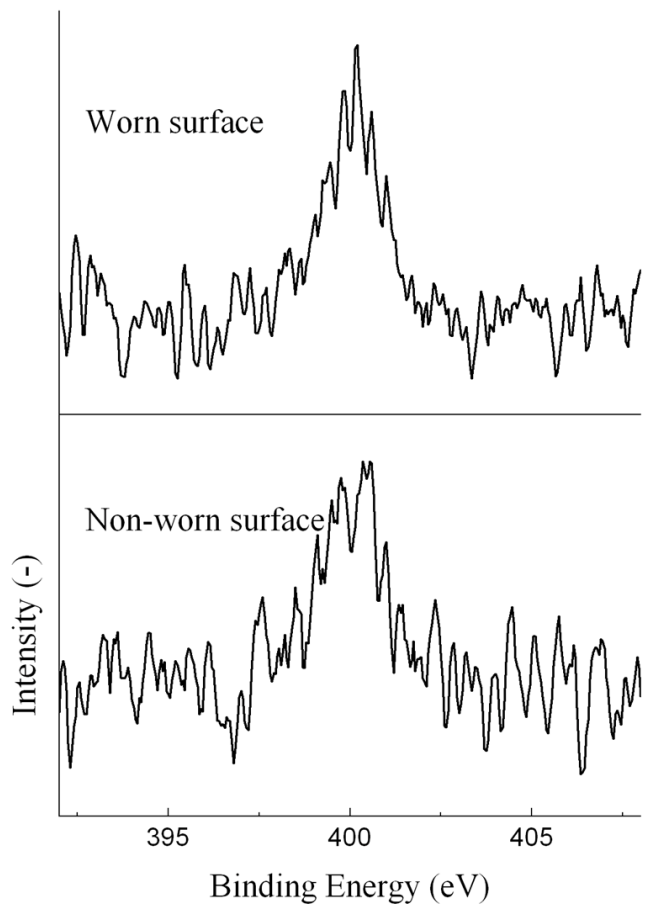




\section{Conclusions}

In this study, experiments were performed to analyze the lubrication properties of two rice husk bio-oil samples with different solid contents and three bio-oil/diesel-oil emulsion samples with different bio-oil contents. The results indicated that the rice husk bio-oil possessed better extreme-pressure, anti-wear and friction-reducing properties than the commercial diesel oil (number zero). The solid char particles played a positive role on the lubrication performance of the bio-oil. The three emulsion samples had better extreme-pressure, but worse friction-reducing properties than the bio-oil. Their lubrication properties were improved with the increasing of the bio-oil contents. In addition, the worn ball surface was covered with complex lubricating films consisting of organic oxygenated deposits, metal oxides, char particles, sulfate and organic nitrogen compounds.

\section{Acknowledgments}

The authors thank the National Natural Science Foundation of China (51106052), Program for New Century Excellent Talents in University (NCET-100-374), Nature Science Foundation of Beijing (3101001), and Fundamental Research Funds for the Central Universities (11ZG08, 11QG25) for financial support.

\section{References}

1. Bridgwater, A.V.; Peacocke, G.V.C. Fast pyrolysis processes for biomass. Renew. Sustain. Energy Rev. 2000, 4, 1-73.

2. Mohan, D.; Pittman, C.U.; Steele, P.H. Pyrolysis of wood/biomass for bio-oil: A critical review. Energy Fuels 2006, 20, 848-889.

3. Czernik, S.; Bridgwater, A.V. Overview of applications of biomass fast pyrolysis oil. Energy Fuels 2004, 18, 590-598.

4. Balat, M. An overview of the properties and applications of biomass pyrolysis oils. Energy Sources Part A 2011, 33, 674-689.

5. Lu, Q.A.; Zhang, Z.F.; Dong, C.Q.; Zhu, X.F. Catalytic upgrading of biomass fast pyrolysis vapors with nano metal oxides: An analytical Py-GC/MS study. Energies 2010, 3, 1805-1820.

6. Lu, Q.; Li, W.Z.; Zhu, X.F. Overview of fuel properties of biomass fast pyrolysis oils. Energy Convers. Manag. 2009, 50, 1376-1383.

7. Chiaramonti, D.; Oasmaa, A.; Solantausta, Y. Power generation using fast pyrolysis liquids from biomass. Renew. Sustain. Energy Rev. 2007, 11, 1056-1086.

8. Chiaramonti, D.; Bonini, A.; Fratini, E.; Tondi, G.; Gartner, K.; Bridgwater, A.V.; Grimm, H.P.; Soldaini, I.; Webster, A.; Baglioni, P. Development of emulsions from biomass pyrolysis liquid and diesel and their use in engines-Part 1: emulsion production. Biomass Bioenergy 2003, 25, $85-99$.

9. Ikura, M.; Stanciulescu, M.; Hogan, E. Emulsification of pyrolysis derived bio-oil in diesel fuel. Biomass Bioenergy 2003, 24, 221-232.

10. Garcia-Perez, M.; Adams, T.T.; Goodrum, J.W.; Geller, D.P.; Das, K.C. Production and fuel properties of pine chip Bio-oil/Biodiesel blends. Energy Fuels 2007, 21, 2363-2372. 
11. Garcia-Perez, M.; Shen, J.; Wang, X.S.; Li, C.Z. Production and fuel properties of fast pyrolysis oil/bio-diesel blends. Fuel Process. Technol. 2010, 91, 296-305.

12. Jiang, X.X.; Ellis, N. Upgrading Bio-oil through Emulsification with Biodiesel: Mixture Production. Energy Fuels 2010, 24, 1358-1364.

13. Jiang, X.X.; Ellis, N. Upgrading Bio-oil through Emulsification with Biodiesel: Thermal Stability. Energy Fuels 2010, 24, 2699-2706.

14. Chiaramonti, D.; Bonini, A.; Fratini, E.; Tondi, G.; Gartner, K.; Bridgwater, A.V.; Grimm, H.P.; Soldaini, I.; Webster, A.; Baglioni, P. Development of emulsions from biomass pyrolysis liquid and diesel and their use in engines - Part 2: tests in diesel engines. Biomass Bioenergy 2003, 25, 101-111.

15. Oasmaa, A.; Leppamaki, E.; Koponen, P.; Levander, J.; Tapola, E. Physical characterisation of biomass-based pyrolysis liquids. In Application of Standard Fuel Oil Analyses; VTT Technical Research Centre: Espoo, Finland, 1997; Volume 9.

16. Xu, Y.F.; Wang, Q.J.; Hu, X.G.; Li, C.; Zhu, X.F. Characterization of the lubricity of bio-oil/diesel fuel blends by high frequency reciprocating test rig. Energy 2010, 35, 283-287.

17. Qiang, L.; Xu-Lai, Y.; Xi-Feng, Z. Analysis on chemical and physical properties of bio-oil pyrolyzed from rice husk. J. Anal. Appl. Pyrolysis 2008, 82, 191-198.

18. Oasmaa, A.; Czernik, S. Fuel oil quality of biomass pyrolysis oils-State of the art for the end user. Energy Fuels 1999, 13, 914-921.

19. Hoekstra, E.; Hogendoorn, K.J.A.; Wang, X.Q.; Westerhof, R.J.M.; Kersten, S.R.A.; van Swaaij, W.P.M.; Groeneveld, M.J. Fast pyrolysis of biomass in a fluidized bed reactor: In situ filtering of the vapors. Ind. Eng. Chem. Res. 2009, 48, 4744-4756.

20. Chen, T.; Wu, C.; Liu, R.; Fei, W.; Liu, S. Effect of hot vapor filtration on the characterization of bio-oil from rice husks with fast pyrolysis in a fluidized-bed reactor. Bioresour. Technol. 2011, $102,6178-6185$.

21. Darmstadt, H.; Garcia-Perez, M.; Adnot, A.; Chaala, A.; Kretschmer, D.; Roy, C. Corrosion of metals by bio-oil obtained by vacuum pyrolysis of softwood bark residues. An X-ray photoelectron spectroscopy and auger electron spectroscopy study. Energy Fuels 2004, 18, 1291-1301.

22. Hua, W.; Jing, L.; Hongling, Y.; Xiangqiong, Z.; Lingbo, L.; Tianhui, R. The tribological behavior of diester-containing polysulfides as additives in mineral oil. Tribol. Int. 2007, 40, $1246-1252$.

(C) 2012 by the authors; licensee MDPI, Basel, Switzerland. This article is an open access article distributed under the terms and conditions of the Creative Commons Attribution license (http://creativecommons.org/licenses/by/3.0/). 